\title{
The Effect of Combined Therapy of Exercise and Nootropic Agent on Cognitive Function in Focal Cerebral Infarction Rat Model
}

\author{
Min-Keun Song, M.D., Hyo-Jeong Seon, M.D., In-Gyu Kim, M.D., Jae-Young Han, M.D., \\ In-Sung Choi, M.D., Ph.D., Sam-Gyu Lee, M.D., Ph.D.
}

\begin{abstract}
Department of Physical \& Rehabilitation Medicine, Research Institute of Medical Sciences, Center for Aging and Geriatrics, Regional CardioCerebroVascular Center, Chonnam National University Medical School \& Hospital, Gwangju 501-757, Korea
\end{abstract}

Objective To investigate the effect of combined therapy of exercise and nootropic agent on cognitive function in a focal cerebral infarction rat model.

Method Forty 10-week old male Sprague-Dawley rats were subjected to photothrombotic cerebral infarction of the left parietal lobe. All rats were randomly divided into 4 groups: group A was photothrombotic cerebral infarction rats without any treatment $(\mathrm{n}=10)$; group $\mathrm{B}$ was photothrombotic cerebral infarction rats with swimming exercise $(\mathrm{n}=10)$; group $\mathrm{C}$ was photothrombotic cerebral infarction rats with oral administration of acetyl-L-carnitine $(\mathrm{n}=10)$; group D was photothrombotic cerebral infarction rats with swimming exercise and oral administration of acetylL-carnitine ( $\mathrm{n}=10)$. Cognitive function was evaluated using the Morris water maze test on the 1st day, and the 1st, 2nd, and 4th week after the induction of cerebral infarction. The activity of superoxide dismutase (SOD) and the level of malondialdehyde (MDA) in the hippocampus were measured. The neuronal cells of the hippocampus were histopathologically evaluated.

Results The escape latency was shorter in groups B, C, and D than in group A. However, the differences were not statistically significant at the 1st, 2nd and 4th week. The activity of SOD was the highest in group D. The level of MDA was the lowest in group D. We observed more normal neuronal cells in groups B, C, and D.

Conclusion The combined therapy of exercise and nootropic agent was helpful in ameliorating oxidative stress in the focal cerebral infarction rat model. However, the effect did not translate into improvement of cognitive function.

Key Words Cerebral infarction, Cognition, Exercise, Nootropic agents

Received February 6, 2012; Accepted April 10, 2012

Corresponding author: Sam-Gyu Lee

Department of Physical \& Rehabilitation Medicine, Chonnam National University Medical School \& Hospital, 42, Jebong-ro, Dong-gu, Gwangju 501-757, Korea

Tel: +82-62-220-5180, Fax: +82-62-228-5975, E-mail: LEE9299@hitel.net (c) This is an open-access article distributed under the terms of the Creative Commons Attribution Non-Commercial License (http:// creativecommons.org/licenses/by-nc/3.0) which permits unrestricted noncommercial use, distribution, and reproduction in any medium, provided the original work is properly cited.

Copyright $\odot 2012$ by Korean Academy of Rehabilitation Medicine

\section{INTRODUCTION}

Stroke is an important health problem because of its high incidence and various disabilities it produces. Stroke patients display various symptoms and disabilities such as cognitive impairment, motor weakness, limitation of activities of daily living (ADLs), and affective disorder. Cognitive impairment or perceptual disorders may 
prevent them from participating in a neurorehabilitation program. Therefore, it is necessary to improve the abilities of cognition and perception for successful rehabilitation. ${ }^{1}$

The blockage or decrease of blood circulation after stroke disturbs the supply of oxygen and energy sources to neuronal cells. This can cause damage to neuronal cells and produce cognitive impairment by increasing oxidative stress. Tissue damage following cerebral ischaemia results from the interaction of complex pathophysiological processes such as excitotoxicity, peri-infarct depolarizations, inflammation as well as apoptosis. ${ }^{2}$ The search for an effective neuroprotective drug has proved to be elusive. ${ }^{3}$ One possible reason for this is the limited drug dosages that can be given because of serious side effects. ${ }^{4}$ Many investigators have paid attention to compounds that are normally present in humans and can be administered at relatively high doses without toxicity such as coenzyme Q and Acetyl-L-carnitine (ALC). ${ }^{5}$ ALC is a naturally occurring substance ${ }^{5}$ and is synthesized in the human brain, liver, and kidney by the enzyme ALCtransferase. ${ }^{6}$ As ALC can cross the blood-brain barrier more efficiently than L-carnitine, it has been widely used in animal and human studies. ${ }^{7}$ ALC has been shown to be beneficial in treating Alzheimer's disease. ${ }^{8}$ ALC is considered to be safe and without significant side effects. ${ }^{6}$

Exercise promotes good health of the cardiovascular, pulmonary, and musculoskeletal systems. Recently, exercise has emerged as a key lifestyle factor in the prevention of dementia and age-related cognitive decline. ${ }^{9,10}$ Exercise can be a non-pharmacological and natural strategy for successful cognitive rehabilitation. ${ }^{11}$ Both ALC and exercise have positive effects on cognitive function. ${ }^{8,11}$ However, there are few reports on whether the combined therapy of exercise and nootropic agent reveals an add-on effect on cognitive function in focal cerebral infarction. Therefore, we aimed to investigate the effect of combined therapy of exercise and nootropic agent on cognitive function in a focal cerebral infarction rat model.

\section{MATERIALS AND METHODS}

\section{Animals}

All animal experiment protocols were carried out in accordance with the guidelines of the Chonnam National University Animal Care and Committee. Forty male Sprague-Dawley rats, aged 10 weeks old, weighing 300-
350 grams (Samtako, Osan, Korea) were used. They were housed at a temperature of $23.0 \pm 1.0^{\circ} \mathrm{C}$ and a humidity of $50 \pm 5 \%$ with a 12 hours light-dark cycle and had free access to food and water ad libitum. All rats were pretrained on the Morris water maze (MWM) and subjected to photothrombotic cerebral infarction of the left parietal lobe. All rats were randomly divided into 4 groups: group A was photothrombotic rats without any treatment $(n=10)$; group B was photothrombotic rats with swimming exercise $(n=10)$; group $C$ was photothrombotic rats with oral administration of ALC (Nicetile ${ }^{\circledR}$, Seoul, Korea) $(n=10)$; group D was photothrombotic rats with swimming exercise and oral administration of ALC $(n=10)$.

\section{Methods}

Photothrombotic cerebral infarction rat model: Photothrombotic cerebral infarction was induced based on the methods described by Watson and colleagues. ${ }^{12}$ Briefly, each rat was anesthetized with $5 \%$ isoflurane and maintained with $2 \%$ isoflurane in $70 \%$ nitrous oxide and $30 \%$ oxygen mixture during the surgical procedure. The operation was performed on a homeothermic plate (Harvard Apparatus, South Natick, USA) to maintain body temperature at $37.5 \pm 0.5^{\circ} \mathrm{C}$. The rat was placed into a stereotactic frame (Stoelting, Wood Dale, USA) in the prone position. After incision and exposure of the scalp, we injected Rose Bangal dye (Sigma-Aldrich Co, St. Louis, USA) $50 \mathrm{mg} / \mathrm{kg}$ into the left femoral vein, and light exposure with KL 1500 LCD (SCHOTT, Hattenbergstrasse, Germany) was given on the left parietal lobe area about $3300 \mathrm{~K}$ and $150 \mathrm{~W}$ for 10 minutes.

Exercise program and administration of medicine: After the induction of photothrombotic cerebral infarction, ALC of $75 \mathrm{mg} / \mathrm{kg}$ was administrated to group C and group $\mathrm{D}$ via an oral feeding tube for 5 consecutive days. The first administration was performed 12 hours after the induction of photothrombotic cerebral infarction.

Exercise started from the next day after the induction of photothrombotic cerebral infarction. Group B and D did free swimming exercise, 20 minutes per day, 5 days a week, for 4 weeks. Group D did swimming exercise after the administration of ALC for a week. Swimming exercise was performed in a round water tank, filled with $30 \mathrm{~cm}$ height of $21^{\circ} \mathrm{C}$ water.

Morris water maze test: Spatial learning and memory were assessed by the MWM test based on the method described by Morris et al. ${ }^{13}$ In brief, the tests were con- 
ducted in a circular metal pool (diameter, $184 \mathrm{~cm}$; height, $60 \mathrm{~cm}$ ), filled with water and maintained at $20-25^{\circ} \mathrm{C}$. The pool was virtually divided into four equal quadrants, and one of them was allocated as the target quadrant. Visual cues were placed at the perimeter of each quadrant. A circular escape platform (diameter, $10 \mathrm{~cm}$; height, $38 \mathrm{~cm}$ ) was placed in the center of the target quadrant. The water level in the pool was adjusted so that the platform was submerged $1 \mathrm{~cm}$ below the surface of the water.

The animals were placed into the water maze facing the maze wall at random entry points, which were equally distributed around the perimeter of the maze. After finding the platform, the rats were allowed to remain there for 10 seconds until the next trial. In the case that the rat could not find the hidden platform within 120 seconds, the rat was guided to the platform and allowed to stay there for 15 seconds. Then, the rat was displaced from the pool, dried and placed back in its holding bin for a period of 5 minutes, after which the second trial was conducted. All groups were acclimated to the above mentioned pretraining for 3 consecutive days right before the induction of photothrombotic cerebral infarction. After the swimming exercise program, MWM test was performed to evaluate spatial memory for three consecutive days. In this trial, rats had to find a platform within 300 seconds. The time to reach the platform (escape latency) and the length of the swim path were recorded automatically by a video tracking system, Ethovision Color-Pro ${ }^{\circledR}$ (Nodulus, Wageningen, The Netherlands).

Biochemical analysis: The oxidant-antioxidant status of the rat brain was assessed by determining the level of malondialdehyde (MDA) and the activity of superoxide dismutase (SOD). Lipid peroxidation was determined by measuring the level of MDA, which is considered to be a standard marker for oxidative lipid damage of tissues. The activity of SOD indicates the level of anti-oxidation in tissues and organs. ${ }^{14,15}$

The left hippocampal tissues were collected and were ultrasonically homogenized in ice-cold $0.9 \% \mathrm{NaCl}$ to produce $1: 9(\mathrm{~g}: \mathrm{L})$ homogenates. After centrifugation at $13,000 \mathrm{rpm}$ for $10 \mathrm{~min}$ at $4.0^{\circ} \mathrm{C}$, the supernatant was collected for measurements of the activity of SOD (Cayman Chemical Company, Ann Arbor, USA) and the level of MDA (OxisResarch ${ }^{\mathrm{TM}}$, Portland, USA). SOD activity was measured by the method of Sun et al. ${ }^{14}$ In brief, $500 \mu \mathrm{L}$ aliquot of hippocampal tissue, together with $50 \mu \mathrm{mol} / \mathrm{L}$ xanthine and $2.5 \mu \mathrm{mol} / \mathrm{L}$ xanthine oxidase in $50 \mu \mathrm{mol} / \mathrm{L}$ potassium phosphate buffer were mixed and incubated at $37^{\circ} \mathrm{C}$ for $40 \mathrm{~min}$, then nitro blue tetrazolium (NBT) was added. The product nitrite produced by the oxidation of oxyamine was measured by monitoring the absorbance at $460 \mathrm{~nm}$ with microplate readers and software (Bio-Tek, Winooski, USA). SOD activity was expressed as $\mathrm{U} / \mathrm{mg}$ protein.

The MDA levels were measured by the method of Draper and Hadley. ${ }^{15}$ Briefly, $1 \mathrm{~mL}$ of $20 \%$ thiobarbituric acid (TBA) and $1 \mathrm{~mL}$ of $1 \%$ TBA reagent were added to $500 \mu \mathrm{L}$ aliquot of hippocampal tissue, then mixed and incubated at $45^{\circ} \mathrm{C}$ for $60 \mathrm{~min}$. After cooling on ice, samples were centrifuged at $13,000 \mathrm{rpm}$ for $10 \mathrm{~min}$ at $4.0^{\circ} \mathrm{C}$, and then the absorbance of the supernatant was read at $586 \mathrm{~nm}$ with microplate readers and software (Bio-Tek, Winooski, USA). The values obtained were compared with a series of standard solutions of MDA. Results were expressed as $\mathrm{nmol} / \mathrm{mg}$ tissue.

Histopathological study: Each rat was transcardially perfused with $100 \mathrm{~mL}$ of saline and followed by $400 \mathrm{~mL}$ of $0.1 \mathrm{~mol} / \mathrm{L}$ phosphate buffer ( $\mathrm{pH} 7.4$ ) with $4 \%$ paraformaldehyde. The brains were removed from the skull and postfixed overnight in the same fixed solution at $4.0^{\circ} \mathrm{C}$. After paraffin embedding, coronal and serial sections (2 $\mu \mathrm{m}$ thick) encompassing brain tissues were taken from each brain. Light microscopic examination (Nikon, Tokyo, Japan) was carried out at a magnification of $\times 200$ and the number of neurons at the CA3 region of the left hippocampus was determined per square millimeter by using a standardized ocular grid. The counting was made by a person blinded to the details of the experiment. The criteria used to distinguish normal from abnormal cells were as follows: (1) cells with regular-shaped soma with clear cytoplasm and intact nuclear membranes were determined as normal and (2) cells with irregular shape, with or without chromatin compaction or a nuclear membrane, DNA marginalization and darkened cytoplasm, or blackened cytoplasm with extensive vacuolarization, were considered to be abnormal. ${ }^{16}$

Statistical analysis: Statistical analyses were carried out with SPSS software program for Windows (version 13.0, Chicago, USA). Data were presented as the mean \pm standard deviation (SD). Repeated measures ANOVA, Kruskall-Wallis test and Wilcoxon Signed Ranks test were used for the data analyses. The differences were considered to be significant when the p-value was less than 0.05 . 


\section{RESULTS}

\section{Behavioral test}

On the next day after the induction of cerebral infarction, escape latencies were 47.2 $220.1 \mathrm{sec}$ in group A, $47.6 \pm 28.5 \mathrm{sec}$ in group $\mathrm{B}, 44.8 \pm 46.6 \mathrm{sec}$ in group $\mathrm{C}$, and $46.1 \pm 28.5 \mathrm{sec}$ in group $\mathrm{D}$. At the 1st week, escape latencies were $43.6 \pm 21.8 \mathrm{sec}$ in group $\mathrm{A}, 40.3 \pm 30.2 \mathrm{sec}$ in group $\mathrm{B}, 40.6 \pm 45.9 \mathrm{sec}$ in group $\mathrm{C}$, and $38.5 \pm 29.7 \mathrm{sec}$ in group $\mathrm{D}$. At the 2nd week, escape latencies were $41.1 \pm 14.9 \mathrm{sec}$ in group A, 39.6 $\pm 26.7 \mathrm{sec}$ in group $\mathrm{B}, 39.5 \pm 30.5 \mathrm{sec}$ in group C, and $37.8 \pm 27.9 \mathrm{sec}$ in group D. At the 4 th week, escape latencies were $40.2 \pm 27.8 \mathrm{sec}$ in group $\mathrm{A}, 38.3 \pm 17.6 \mathrm{sec}$ in group $B, 37.7 \pm 20.0 \mathrm{sec}$ in group $\mathrm{C}$, and $35.9 \pm 23.4 \mathrm{sec}$ in group D. The escape latency was shorter in groups $\mathrm{B}, \mathrm{C}$, and $\mathrm{D}$ than in group $\mathrm{A}$. However, the differences were not significant at the 1st, 2nd, and 4th week ( $p>0.05$ ) (Fig. 1). There were no significant differences in the length of swim path among all groups at the 1st, 2nd, and 4th week ( $>0.05)$.

\section{Biochemical analysis}

1) The activity of SOD was significantly different among all groups $(p=0.000)$. It was more elevated in groups $B$, $\mathrm{C}$, and D than in group $\mathrm{A}(\mathrm{p}=0.001, \mathrm{p}=0.001, \mathrm{p}=0.001)$. Group D was more elevated than group $\mathrm{B}$ and groups $\mathrm{C}$ $(\mathrm{p}=0.018, \mathrm{p}=0.002)$ (Fig. 2).

2) The level of MDA was significantly different among all groups $(\mathrm{p}=0.002)$. It was more decreased in groups $B$,

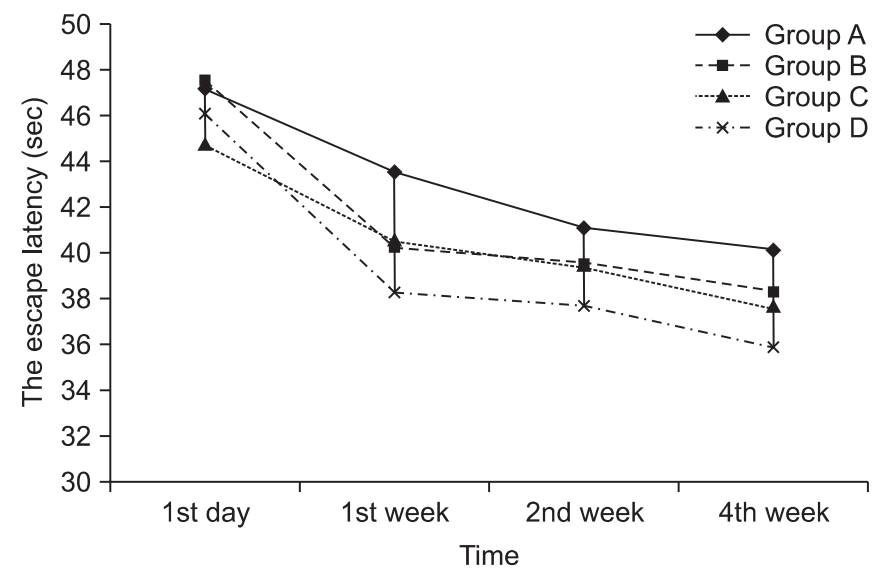

Fig. 1. The escape latency was shorter in groups B, C and $\mathrm{D}$ than group $\mathrm{A}$. However, the differences were not statistically significant at the 1st, 2 nd and 4 th week after the induction of photothrombotic cerebral infarction in experimental rats.
C, and D than in group A $(\mathrm{p}=0.009, \mathrm{p}=0.002, \mathrm{p}=0.007)$. However, there were no significant differences among groups B, C, and D ( $\mathrm{p}>0.05$ ) (Fig. 3).

\section{Histopathological study}

Hematoxylin \& Eosin staining showed severe cortical damage of the left parietal lobe in all experimental rats (Fig. 4). The number of normal neuronal cells in the CA3 region of the left hippocampus was significantly different among all groups $(p=0.017)$ (Table 1$)$. It was more increased in groups $\mathrm{B}, \mathrm{C}$, and $\mathrm{D}$ than in group $\mathrm{A}(\mathrm{p}<0.05)$. However, there were no significant differences among

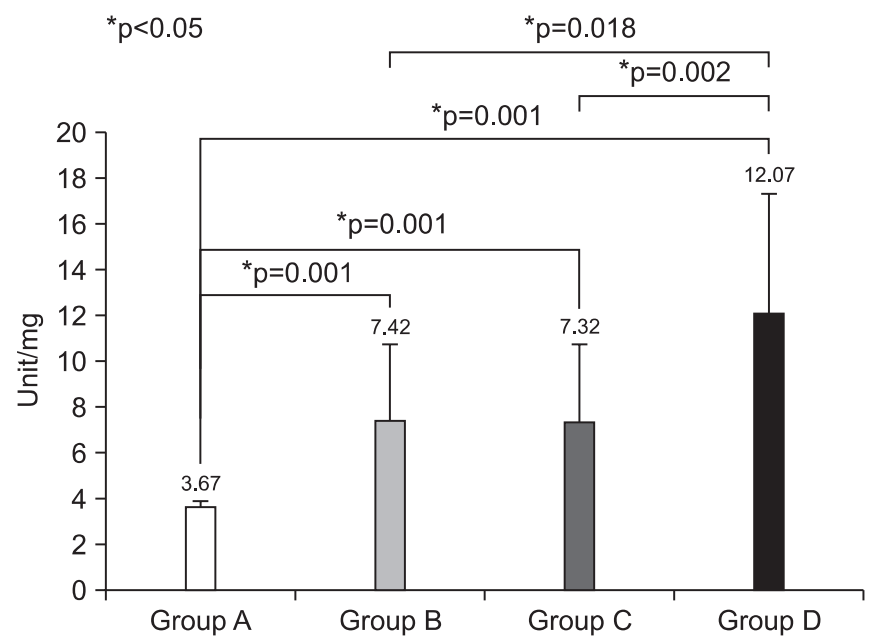

Fig. 2. The activity of superoxide dismutase was more elevated in groups B, C, and D than group A. Group D was more elevated than groups $\mathrm{B}$ and $\mathrm{C}$.

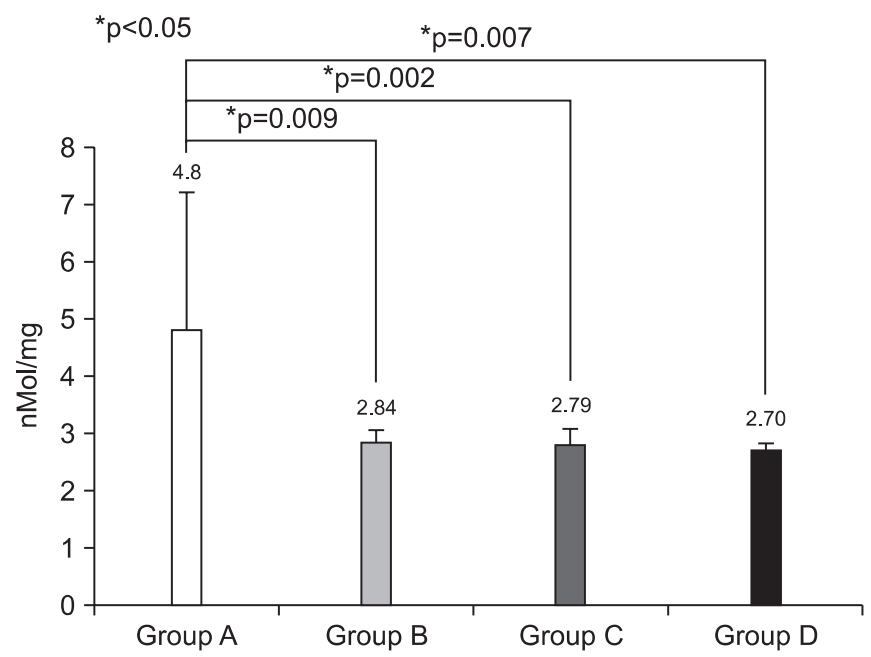

Fig. 3. The level of malondialdehyde was more decreased in groups $\mathrm{B}, \mathrm{C}$, and $\mathrm{D}$ than group $\mathrm{A}$. There were no significant differences among groups $\mathrm{B}, \mathrm{C}$, and $\mathrm{D}$. 


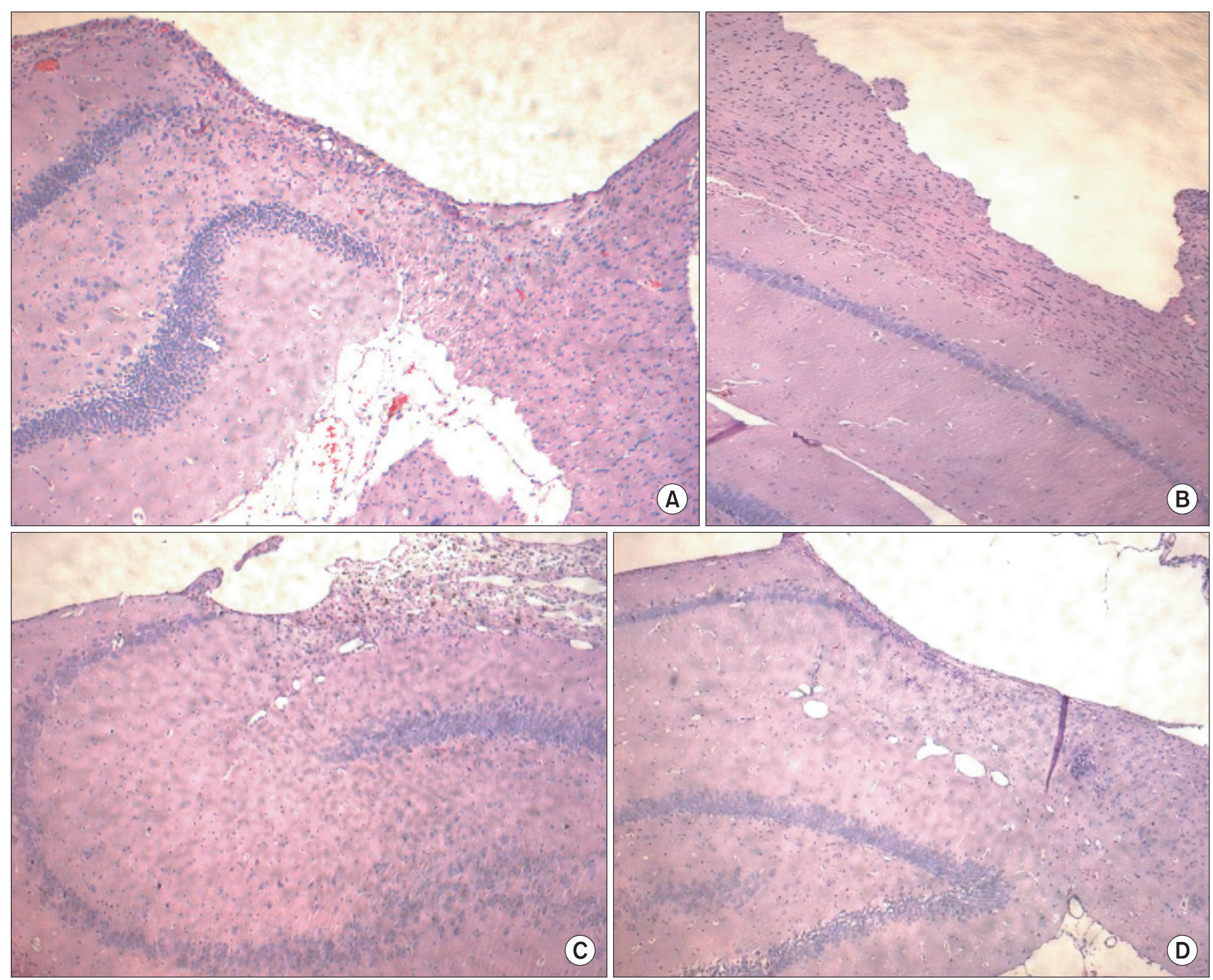

Fig. 4. Severe cortical damage is observed in the left parietal lobe in all groups (the left parietal cortex, H\&E stain, $\times 40$ ).

Table 1. The Number of Normal Neuronal Cells

\begin{tabular}{cc}
\hline Groups & Normal neuronal cells $(\mathbf{n})$ \\
\hline A & $19.25 \pm 0.96$ \\
B & $31.00 \pm 0.82^{*}$ \\
C & $29.75 \pm 0.96^{*}$ \\
D & $30.50 \pm 1.29^{*}$ \\
\hline
\end{tabular}

${ }^{*} \mathrm{p}=0.000$ compared with group A

groups B, C, and D ( $>0.05)$ (Fig. 5).

\section{DISCUSSION}

Excitotoxicity and oxidative stress are toxic events com- monly associated with neuronal cell death in neurodegenerative diseases. ${ }^{17}$ Any medicine, which has antioxidant defense and mitochondrial reductive capacities, will be a valuable tool to preserve neuronal cells in toxic conditions. ${ }^{17}$ Many kinds of medicines were reported to be neuroprotective after ischemic brain injury in animal studies. ${ }^{18-20}$ However, their clinical usage was limited because of drug side effects or lack of effectiveness in human trials. It was reported that administration of ALC in the cerebral ischemia rat model could improve spatial memory. ${ }^{21}$ ALC is a naturally occurring substance without serious side effects and is a promising candidate in cognitive rehabilitation. ${ }^{5}$ Recent studies suggested that ALC improves spatial working memory, reduces oxida- 


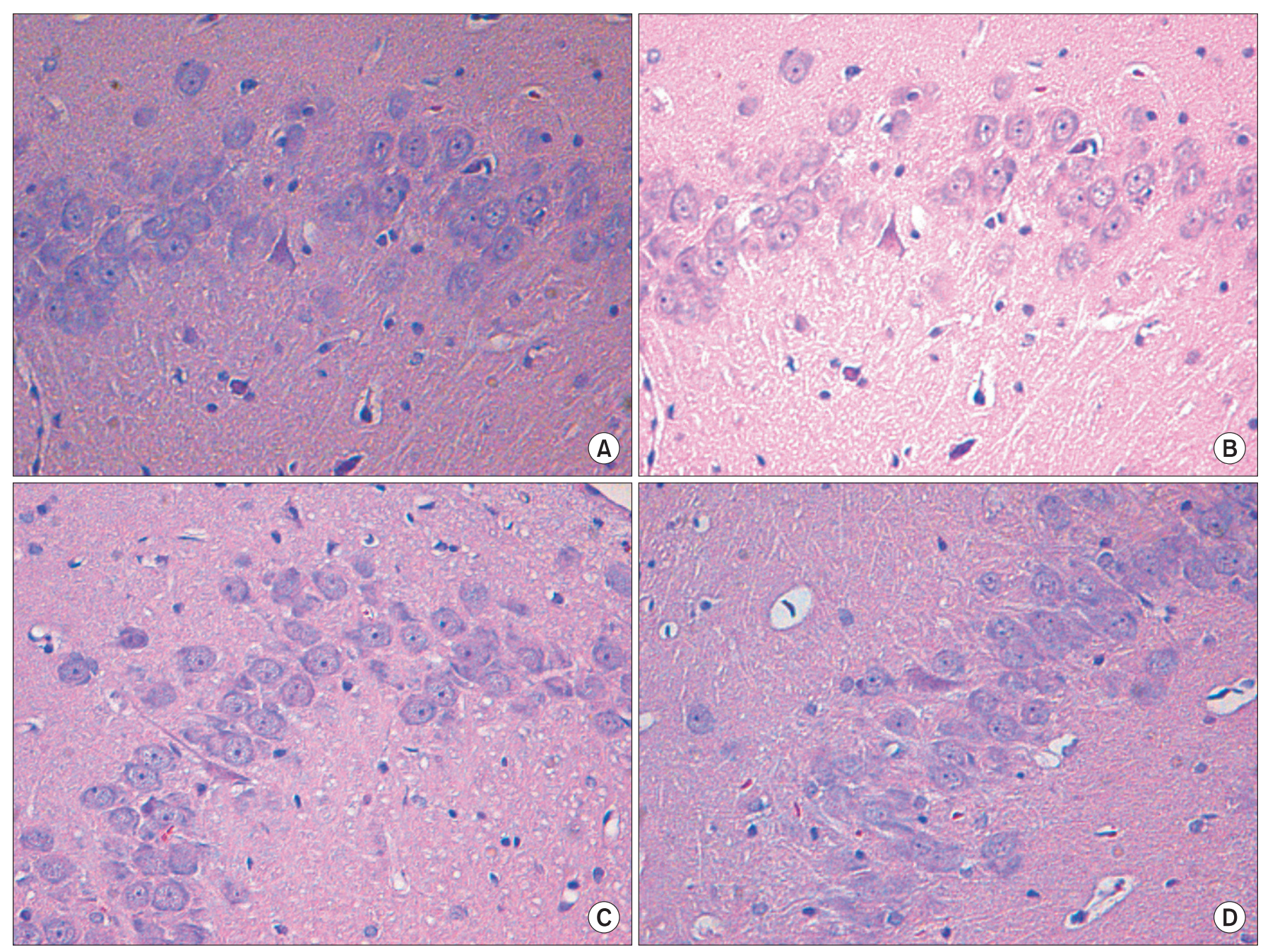

Fig. 5. A greater number of normal neuronal cells are observed in groups B, C, and D (CA3 region of hippocampus, H\&E stain, $\times 200)$

tive stress, and inhibits the apoptotic cascade induced by hypoxia and hippocampal neuronal cell death in response to glutamate exposure. ${ }^{22,23}$ The acetyl component of ALC is metabolized in the brain, thereby promoting oxidative cerebral energy production and minimizing anaerobic glycolysis and lactic acidosis. ALC protects against oxidative stress indirectly through its amelioration of tissue lactic acidosis, a condition that promotes the formation of reactive oxygen species (ROS). ALC also protects against excitotoxic cell death directly through antagonism of glutamate receptors. ${ }^{5}$ ALC facilitates the uptake of acetyl CoA into the mitochondria during fatty acid oxidation and enhances acetylcholine production. ${ }^{6}$ It also increases cholinergic synaptic transmission and improves cognitive function in aging rats. ${ }^{24}$ In the present study, ALC administration alone resulted in slight shortening of escape latency, elevated activity of SOD, decreased level of MDA, and higher numbers of normal hippocampal neuronal cells compared to the control group. ALC may lead to elevated activity of SOD, which is involved in the direct elimination of free radicals produced by oxidative stress. ${ }^{25}$ Our results suggest that ALC may improve cognitive function by decreasing oxidative stress and preventing hippocampal neuronal cell death.

Exercise has positive effects on the improvement of cognitive function, especially learning and memory. There are a few studies on the effects of exercise on oxidative damage. However, the findings are conflicting. ${ }^{26,27} \mathrm{~A}$ single bout of exercise induced the formation of ROS and oxidative stress. ${ }^{28}$ However, regular exercise increased resistance against ROS induced lipid peroxidation, and the activity of the proteasome complex, and decreased the 
accumulation of oxidative proteins and DNA damage. ${ }^{29}$ The increase in the activity of antioxidant enzymes in the brain as a response to regular physical exercise is most probably due to the excess formation of free radicals. ${ }^{27,30}$ Radak et al. ${ }^{31}$ suggested that regular exercise improved cognitive function in parallel with the decreased accumulation of oxidized proteins. In this study, the activity of SOD was increased in the three treatment groups. Especially, swimming exercise increased the activity of SOD more than ALC administration alone. The activity of SOD was most increased in the combined therapy group, which showed an add-on effect. This revealed that administration of ALC, swimming exercise, and combined therapy would protect the brain from free radicals after ischemic brain injury and suggested that the similar mechanisms of exercise and ALC would have a positive add-on effect on cognitive function.

Exercise enhances neurogenesis in the hippocampal dentate gyrus, which may contribute to cognitive improvement. ${ }^{32}$ The effects on cognitive function according to the type of exercise are controversial. ${ }^{33,34} \mathrm{Ra}$ et al..$^{33}$ demonstrated that swimming as well as treadmill running increased neurogenesis in the dentate gyrus of rats. However, van Praag et al..$^{34}$ reported that swimming exercise did not affect cell proliferation. In the present study, a higher number of normal neuronal cells were seen in the three treatment groups compared with the control group. Swimming exercise would be helpful for hippocampal neurogenesis. However, the add-on effect was not evident in the combined therapy group in terms of hippocampal neurogenesis.

\section{CONCLUSION}

One of the most important findings was that both regular exercise and ALC, and moreover, the combined effects of these two natural treatments, decreased oxidative stress and increased hippocampal neurogenesis. However, these changes did not translate into improvement of cognitive function in the photothrombotic cerebral infarction rat model. Further studies using a large sample size would be needed to demonstrate the potentially important roles in natural and physiological factors, such as natural substances and regular exercise, have in cognitive function.

\section{ACKNOWLEDGEMENTS}

This study was supported by a grant of the Korea Healthcare Technology R\&D Project, Ministry for Health, Welfare \& Family Affairs, Republic of Korea (A084869).

\section{REFERENCES}

1. Moon SK, Shin YI, Kim HI, Lee MC, Jin CY, Lee S, Yoon KH, Cai QY, Chung GH. Chronological changes in cerebral infarction of photochemical thrombosis model: magnetic resonance imaging and histopathological correlation. J Korean Acad Rehab Med 2006; 30: 447-454

2. Dirnagl U, Iadecola C, Moskowitz MA. Pathobiology of ischaemic stroke: an integrated view. Trends Neurosci 1999; 22: 391-397

3. Balduini W, De Angelis V, Mazzoni E, Cimino M. Simvastatin protects against long-lasting behavioral and morphological consequences of neonatal hypoxic/ ischemic brain injury. Stroke 2001; 32: 2185-2191

4. Shake JG, Peck EA, Marban E, Gott VL, Johnston MV, Troncoso JC, Redmond JM, Baumgartner WA. Pharmacologically induced preconditioning with diazoxide: a novel approach to brain protection. Ann Thorac Surg 2001; 72: 1849-1854

5. Zanelli SA, Solenski NJ, Rosenthal RE, Fiskum G. Mechanisms of ischemic neuroprotection by AcetylL-carnitine. Ann N Y Acad Sci 2005; 1053: 153-161

6. Acetyl-L-Carnitine. Monograph. Altern Med Rev 2010; 15: 76-83

7. Kidd PM. A review of nutrients and botanicals in the integrative management of cognitive dysfunction. Altern Med Rev 1999; 4: 144-161

8. White HL, Scates PW. Acetyl-L-carnitine as a precursor of acetylcholine. Neurochem Res 1990; 15: 597-601

9. Kiraly MA, Kiraly SJ. The effect of exercise on hippocampal integrity: review on recent research. Int J Psychiatry Med 2005; 35: 75-89

10. Cotman CW, Berchtold NC, Christie LA. Exercise builds brain health: key roles of growth factor cascades and inflammation. Trends Neurosci 2007; 30: 464-472

11. Ang ET, Dawe GS, Wong PT, Moochhala S, Ng YK. Alteration in spatial learning and memory after forced exercise. Brain Res 2006; 1113: 186-193 
12. Watson BD, Dietrich WD, Busto R, Wachtel MS, Ginsberg MD. Induction of reproducible brain infarction by photochemically initiated thrombosis. Ann Neurol 1985; 17: 497-504

13. Morris RG, Garrud P, Rawlins JN, O'Keefe J. Place navigation impaired in rats with hippocampal lesions. Nature 1982; 297: 681-683

14. Sun Y, Oberley LW, Li Y. A simple method for clinical assay of superoxide dismutase. Clin Chem 1988; 34: 497-500

15. Drapper HH, Hadley M. Malondialdehyde determination as index of lipid peroxidation. Methods Enzymol 1990; 186: 421-431

16. Rogers HJ. Cell death and organ development in plants. Curr Top Dev Biol 2005; 71: 225-261

17. Elinos-Calderón D, Robledo-Arratia Y, Pérez-De La Cruz V, Pedraza-Chaverrí J, Ali SF, Santamaría A. Early nerve ending rescue from oxidative damage and energy failure by L-carnitine as post-treatment in two neurotoxic models in rat: recovery of antioxidant and reductive capacities. Exp Brain Res 2009; 197: 287-296

18. Yin YY, Liu H, Cong XB, Liu Z, Wang Q, Wang JZ, Zhu LQ. Acetyl-L-carnitine attenuates okadaic acid induced tau hyperphosphorylation and spatial memory impairment in rats. J Alzheimers Dis 2010; 19: 735-746

19. Ueno Y, Zhang N, Miyamoto N, Tanaka R, Hattori N, Urabe T. Edaravone attenuates white matter lesions through endothelial protection in a rat chronic hypoperfusion model. Neuroscience 2009; 162: 317-327

20. Balduini W, De Angelis V, Mazzoni E, Cimino M. Simvastatin protects against long-lasting behavioral and morphological consequences of neonatal hypoxic/ ischemic brain injury. Stroke 2001; 32: 2185-2191

21. Barhwal K, Hota SK, Jain V, Prasad D, Singh SB, Ilavazhagan G. Acetyl-1-carnitine (ALCAR) prevents hypobaric hypoxia-induced spatial memory impairment through extracellular related kinase-mediated nuclear factor erythroid 2-related factor 2 phosphorylation. Neuroscience 2009; 161: 501-514

22. Barhwal K, Singh SB, Hota SK, Jayalakshmi K, Ilavazhagan G. Acetyl-L-carnitine ameliorates hypobaric hypoxic impairment and spatial memory deficits in rats. Eur J Pharmacol 2007; 570: 97-107

23. Forloni G, Angeretti N, Smiroldo S. Neuroprotective activity of acetyl-L-carnitine: studies in vitro. J Neurosci Res 1994; 37: 92-96
24. Ando S, Tadenuma T, Tanaka Y, Fukui F, Kobayashi S, Ohashi Y, Kawabata T. Enhancement of learning capacity and cholinergic synaptic function by carnitine in aging rats. J Neurosci Res 2001; 66: 266-271

25. Annadurai T, Vigneshwari S, Thirukumaran R, Thomas PA, Geraldine P. Acetyl-L-carnitine prevents carbon tetrachloride-induced oxidative stress in various tissues of Wistar rats. J Physiol Biochem 2011; 67: 519530

26. Suzuki M, Katamine S, Tatsumi S. Exercise-induced enhancement of lipid peroxide metabolism in tissues and their transference into the brain in rat. J Nutr Sci Vitaminol 1983; 29: 141-151

27. Radak Z, Asano K, Inoue M, Kizaki T, Oh-Ishi S, Ohno H. Acute bout of exercise does not alter the antioxidant enzyme status and lipid peroxidation of rat hippocampus and cerebellum. Pathophysiology 1995; 2 : 243-245

28. Davies KJ, Quintanilha AT, Brooks GA, Packer L. Free radicals and tissue damage produced by exercise. Biochem Biophys Res Commun 1982; 107: 1198-1205

29. Radak Z, Kaneko T, Tahara T, Nakamoto H, Ohno H, Sasvari M, Nyakas C, Goto S. The effect of exercise training on oxidative damage of lipids, proteins, and DNA in rats skeletal muscle: evidence for beneficial outcomes. Free Radical Biol Med 1999; 27: 69-74

30. Somani SM, Ravi R, Rybak LP. Effect of exercise training on antioxidant system in brain regions of rat. Pharmacol Biochem Behav 1995; 50: 635-639

31. Radak Z, Kaneko T, Tahara S, Nakamoto H, Pucsok J, Sasvari M, Nyakas C, Goto S. Regular exercise improves cognitive function and decreases oxidative stress in rat brain. Neurochem Int 2001; 38: 17-23

32. van Praag H, Shubert T, Zhao C, Gage FH. Exercise enhances learning and hippocampal neurogenesis in aged mice. J Neurosci 2005; 25: 8680-8685

33. Ra SM, Kim H, Jang MH, Shin MC, Lee TH, Lim BV, Kim EH, Kim KM, Kim SS. Treadmill running and swimming increase cell proliferation in the hippocampal dentate gyrus of rats. Neurosci Lett 2002; 333: 123-126

34.van Praag H, Kemperamann G, Gage FH. Running increases cell proliferation and neurogenesis in the adult mouse dentate gyrus. Nature Neurosci 1999; 2 : 266-270 